Corrigendum

\title{
Corrigendum to "The Treatment of Giant Periurethral Condyloma in Pregnancy Using an Ultrasonic Thermal Scalpel: A Case Report and New Single Session Treatment Option”
}

\author{
Ali Yavuzcan, ${ }^{1}$ Mete Çağlar, ${ }^{1}$ Hakan Turan, ${ }^{2}$ Ali Tekin, ${ }^{3}$ Gizem Yavuzcan, ${ }^{2}$ Seren Topuz, \\ Serdar Dilbaz, ${ }^{1}$ Yusuf Üstün, ${ }^{1}$ Cihangir Aliağaoğlu, ${ }^{2}$ and Selahattin Kumru ${ }^{1}$ \\ ${ }^{1}$ Department of Obstetrics \& Gynaecology, Düzce University Faculty of Medicine, 81000 Düzce, Turkey \\ ${ }^{2}$ Department of Dermatology, Düzce University Faculty of Medicine, 81000 Düzce, Turkey \\ ${ }^{3}$ Department of Urology, Düzce University Faculty of Medicine, 81000 Düzce, Turkey \\ Correspondence should be addressed to Ali Yavuzcan; draliyavuzcan@yahoo.com \\ Received 19 October 2015; Accepted 20 October 2015 \\ Copyright (C) 2015 Ali Yavuzcan et al. This is an open access article distributed under the Creative Commons Attribution License, \\ which permits unrestricted use, distribution, and reproduction in any medium, provided the original work is properly cited.
}

In the paper "The Treatment of Giant Periurethral Condyloma in Pregnancy Using an Ultrasonic Thermal Scalpel: A Case Report and New Single Session Treatment Option" [1], the authors' order is corrected as above.

\section{References}

[1] A. Yavuzcan, M. Çağlar, H. Turan et al., "The treatment of giant periurethral condyloma in pregnancy using an ultrasonic thermal scalpel: a case report and new single session treatment option," Case Reports in Obstetrics and Gynecology, vol. 2015, Article ID 792412, 4 pages, 2015. 


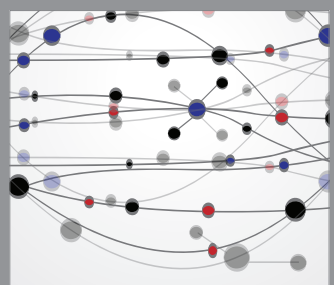

The Scientific World Journal
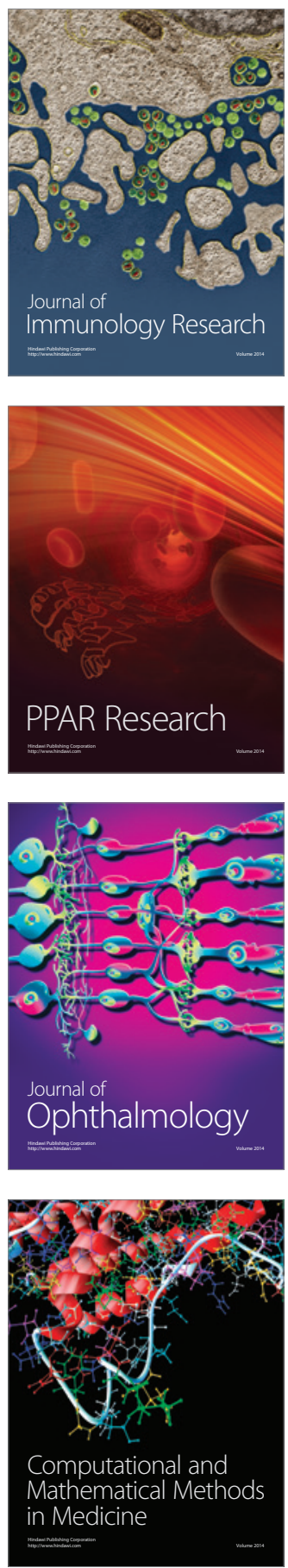

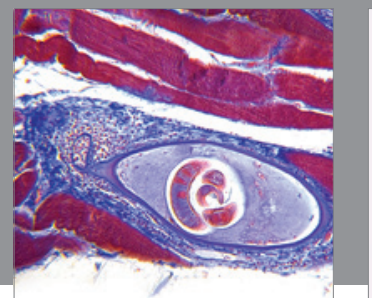

Gastroenterology

Research and Practice
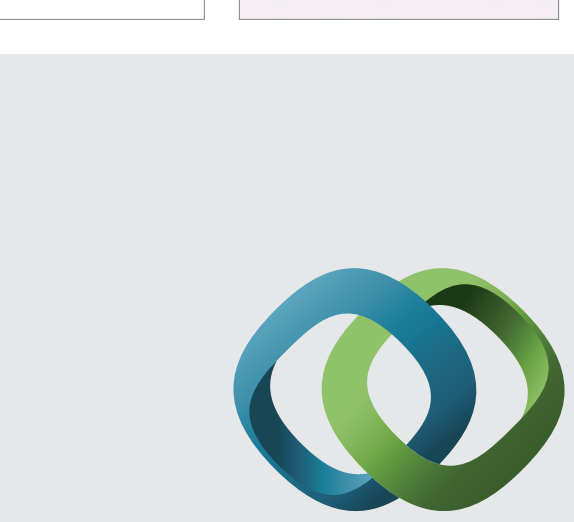

\section{Hindawi}

Submit your manuscripts at

http://www.hindawi.com
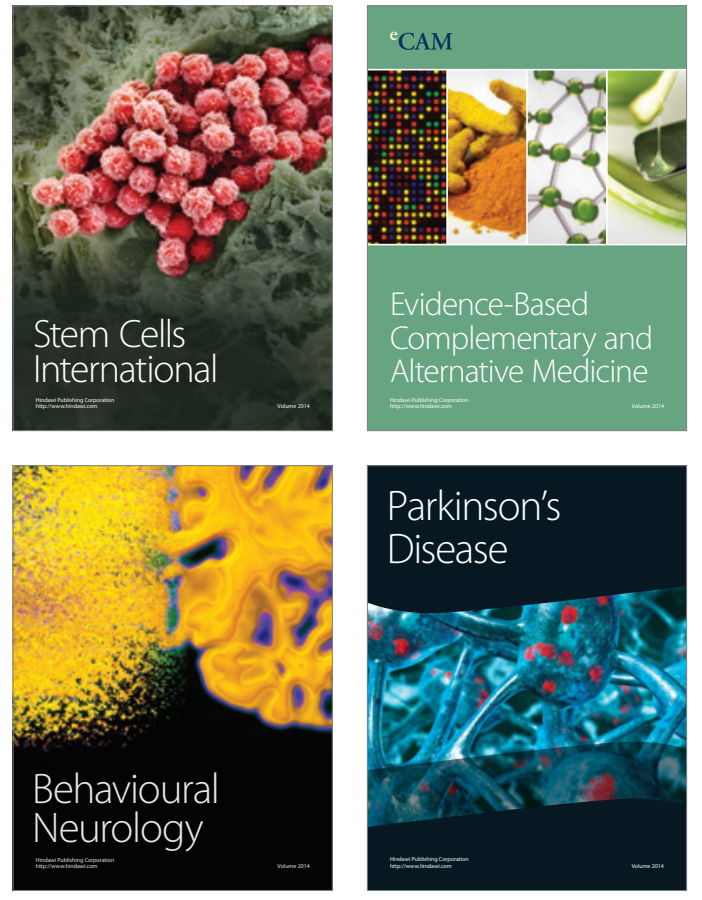
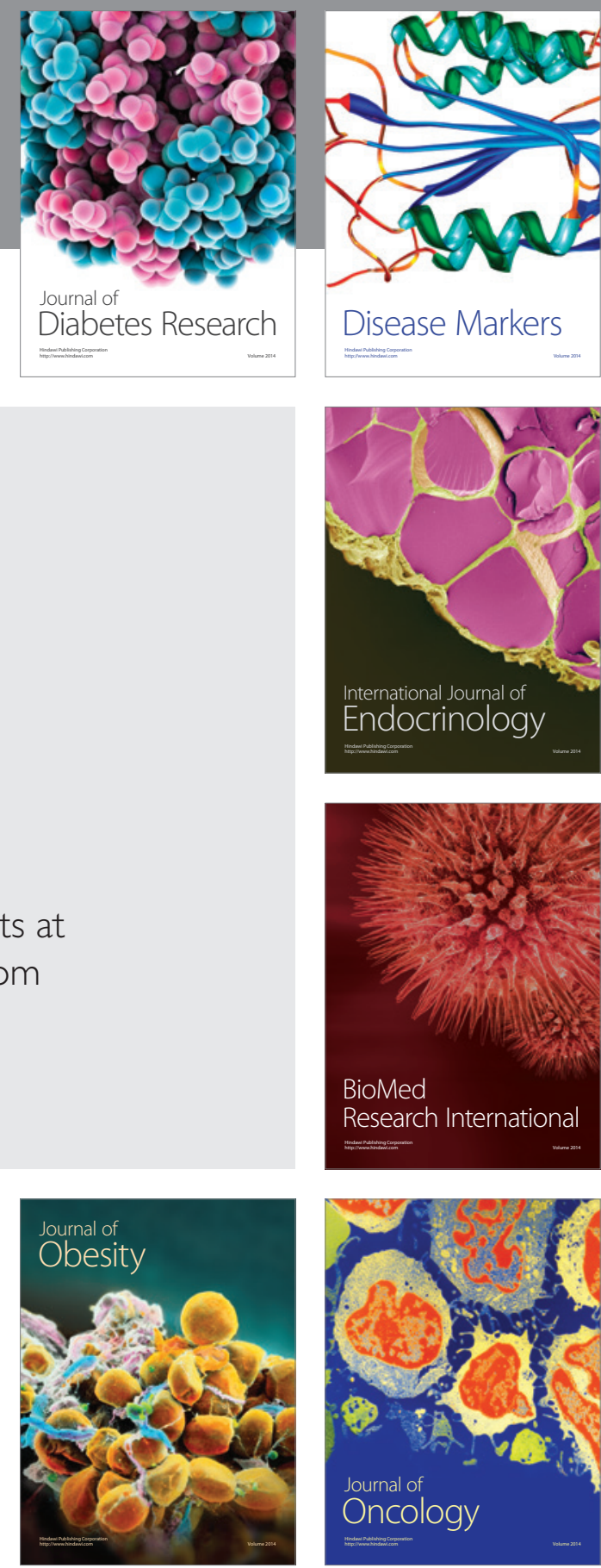

Disease Markers
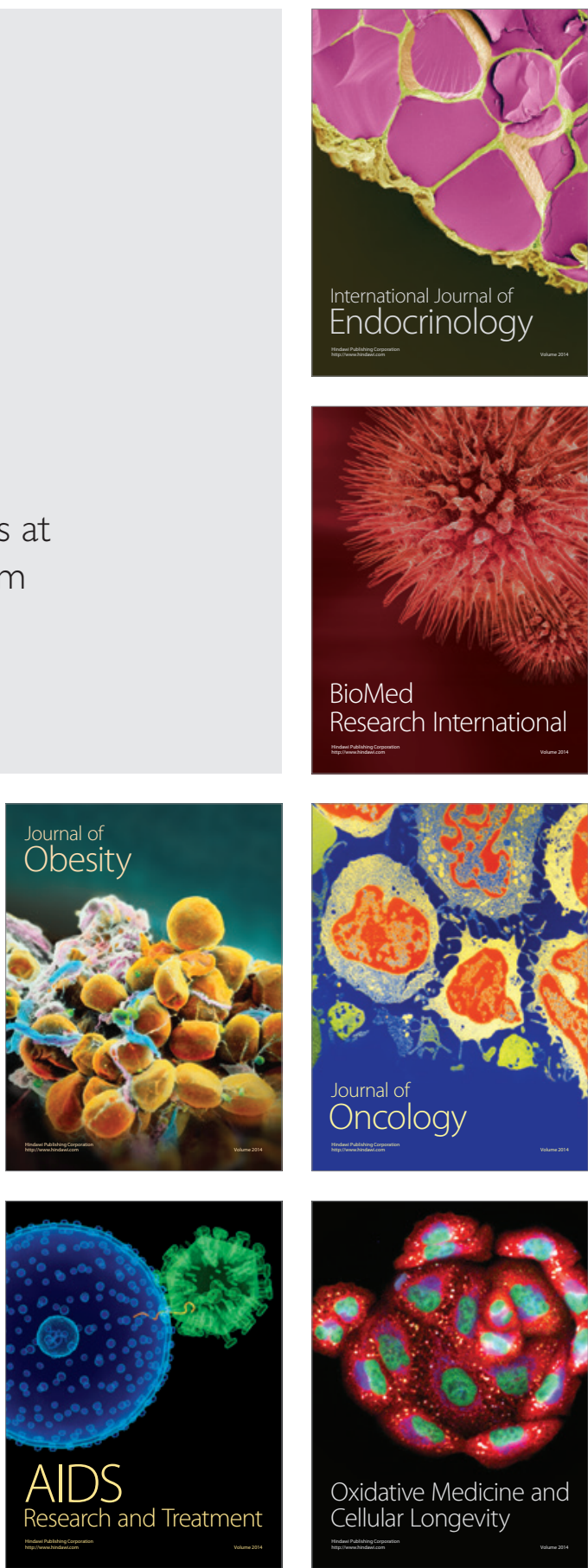